\title{
Chatter stability prediction for CNC machine tool in operating condition through operational modal analysis
}

\author{
M. Lamraoui ${ }^{1,2,3 a}$, M. El Badaoui ${ }^{1,2,3}$ And F. Gullleti ${ }^{1,2,3}$ \\ 1 Université de Lyon, 42023 Saint Etienne, France \\ 2 Université de Saint Etienne, Jean Monnet, 42000 Saint-Etienne, France \\ 3 LASPI, IUT de Roanne, 42334 Roanne, France
}

Received 2 March 2015, Accepted 22 May 2015

\begin{abstract}
The stability of high-speed machining operations is crucial in machining process and presents a key issue for insuring better surface quality, increasing productivity and protecting both machines and safe workpiece. Stability prediction in milling is based on experimental modal analysis by the estimation of frequency response functions using a tap test. One limitation of accurately estimating the stability using such approach is the change in process and the dynamic characteristics of the machine tool under operation. This paper proposes a signal processing procedure applied to vibrations in machining process in order to obtain spindle's modal variations in operation. The novelty of the proposed approach consists in removing "virtual modes", caused by harmonic excitations, from the system response before performing operational modal analysis. Thus, the proposed procedure combines two existing techniques that are the Cepstral Editing Procedure and the Least Square Complex Exponential. The importance of the developed methodology is in adjusting the chatter stability criterion for material removal on a dynamic basis. The main work is given as follows: first of all, the Cepstral Editing Procedure (CEP) algorithm is applied on the acceleration signals for removing deterministic vibrations caused by harmonic excitations. The residue signal is the system response to white noise excitation. The frequency response functions (FRF) are then calculated from these signals at different cutting conditions. The outcome is compared to the result of impact test on the spindle under static condition. Similarities in the form of FRFs obtained in static and operational conditions validate the proposed approach while variations of modal properties under different cutting conditions are successfully captured. Secondly, the Least Square Complex Exponential (LSCE) method in operational modal analysis is invoked to find the natural frequencies and damping ratios of the system at different spindle speeds and cutting depths. Then, the dynamic chatter stability lobes diagrams (SLD) are established which account for spindle's speed-dependent modal variations. A significant change in the stability border is observed which is interesting in machining fields. It will be shown that some depths of cut that are stable with static stability lobes become unstable with dynamic stability lobes and vice versa.
\end{abstract}

Key words: High speed machining / OMA / EMA / CPE / LSCE / modal parameters

\section{Introduction}

In last years, manufacturers have shown great interest to increase productivity and surface quality of pieces by using high speed milling machine centers.

Many problems that occur during high speed milling are related to the instability of the cutting process. This instability causes poor surface finish, an increase rate of tool wear, a bad dimensional accuracy and a possible breakage of cutting tool and spindle tool unit.

The unstable phenomenon, known as chatter [1-4] is a self-excited vibration that can arise in machining process

\footnotetext{
${ }^{a}$ Corresponding author:

lamraoui.mourad@hotmail.fr
}

at specific combinations of cutting parameters. The studies on chatter go back to the 1950s with Tobia, Tlusty and Polacek [1-4], who have explained the regenerative chatter in orthogonal cutting and developed the two dimensional stability lobes theory. They have made remarkable discovery that the main source of self-excited regenerative vibration/chatter is related to the structural dynamics of the machine tool-workpiece system and the feedback response between subsequent cuts [5].

The construction of stability lobes diagrams requires prior information on: (1) the response function of the system (cutting tool/ tool holder/ machine tool) that presents the key variable in the dedication of the stability limit [6], and (2) the cutting coefficients that depend on the material used. However, the modeling of the 


\section{Acronyms}

\begin{tabular}{|ll|}
\hline AR & Autoregressive model \\
CEP & Cepstral Editing Procedure \\
EMA & Experimental Modal Analysis \\
FRF & Fourier Transform \\
IRF & Frequency Response Functions \\
LSCE & Impulse Response Function \\
MDoF & Least Square Complex Exponential \\
OMA & Multi Degree of freedom \\
SLD & Operational Modal Analysis \\
$H$ & Stability Lobes Diagram \\
& Frequency Response Function of \\
$A(r), A(r) *$ & a MDoF system \\
$r$ & Residue of mode $r$, respectively (complex) \\
$N$ & Subscript for mode counter \\
$s$ & Total number of modes \\
$s_{r}, s_{r} *$ & Laplace variable \\
& Eigenvalue of a system, respectively \\
$h_{i j}$ & (complex) \\
$i j$ & Impulse response function provided by \\
$k \Delta$ & IRF data samples \\
$z$ & Subscript of the response function \\
$\beta_{i}$ & Spaced time interval for sampling \\
$w_{r}$ & ( $k=1,2 \ldots, 2 N)$ \\
$\xi_{r}$ & $z$ transform variable \\
& Real coefficients of $z$ polynomial \\
& Undamped natural frequency for mode $r$ \\
& Damping ratio for mode $r$ \\
\end{tabular}

identification process stability lobes diagram is not an easy task, because of the high number of freedom degrees of structure, multiple cutting teeth, variable cutting force and chip direction.

Stability limit studies have two important assumptions. First of all, many authors have studied it through machine behaviour, assuming a rigid workpiece [6]. The response function is designed through models or experimental approaches like tap test. Secondly, most of the previous models and even the tap test made the supposition that spindle-tool set dynamics do not change over the full spindle speed range. These assumptions need to be reviewed in high speed machining where many factors may be involved and affect the modal parameters [5, 7-9]. In particular, gyroscopic effects and centrifugal forces on both bearings and spindle shaft induce spindle speed dependent dynamics changes $[7,10]$.

Regarding the experimental approaches, Faassen et al. [11] and Schmitz et al. [9] have considered the speed dependent spindle dynamics on the basis of experimental response function identification at different spindle speeds. Their method uses the impulse hammer excitation and contact free (capacitive probe) response measurement of a rotating tool at different discrete spindle speeds. The results revealed speed dependent variations in spindle dynamics and hence in the stability limit.

Regarding the modelling approaches, Alfares et al. [12] have used a mathematical model based on a dynamic system with five degrees of freedom. This model studies the effects of axial preloading of angular contact ball bear- ings on the vibration behavior of grinding machine spindles. The results have shown that as the initial preload increases, the stiffness of the bearings increases and consequently, the dominant frequencies of the system shift to higher values.

The studies done by Jorgenson et al. [13] have confirmed that at high speed thermal expansion, the loading condition and bearings material type can play an important role in bearing stiffness. These parameters depend nonlinearly with the spindle dynamic response and impact on the dynamic behaviour of the machine.

Aktuk et al. [14] have studied the radial and axial vibrations of a rigid shaft supported by a pair of angular contact ball bearings. They have investigated the effect on the shaft vibration by varying the preload and the number of balls in the bearings when the bearings are perfect. Results have shown that the preload and the number of balls in a ball bearing are two important governing parameters affecting its dynamic behaviour and should be considered at the design stage.

Jui-Pin Hung et al. [15] have developed a finite element model to evaluate the dynamic characteristics and machining stability of vertical milling system. The results of the finite element simulations have revealed that linear guides with different preloads greatly affect the dynamic behavior and milling stability of the vertical column spindle head system. These results were validated by performing vibration and machining tests.

Gagnol et al. [16] have developed an integrated spindle finite-element model (FEM) to characterize the dynamic behaviour of a motorized machine tool spindle. The authors have demonstrated a dependence of dynamic stiffness on spindle speed. Then, they integrated the proposed speed-dependent response function into a chatter vibration stability approach of Budak-Altintas [6] to predict a dynamic stability lobe diagram. Hence, for an accurate stability limit prediction, the modal parameters must be well evaluated.

Traditionally, the Frequency Response Function (FRF) is measured by exciting the spindle at the tool tip by impact hammers or shakers manually [17]. There have been several attempts to measure the FRFs automatically. The authors in Reference [18] have used a piezoactuator connected in series with a force measurement sensor and a displacement sensor to estimate the FRF at tool tip at standstill. The authors in Reference [19] have used an electromagnetic actuator to excite the shaft and measure the displacement with a non-contact probe at various rotating speeds. Various authors have used an impact hammer for exciting the shaft. This type of excitation is also used for hitting the rotating shaft under high speeds as presented in Reference [20]. However, the following difficulties need to be kept in mind [21]:

- Only a small part of the rotating shaft is accessible for testing, hence modeling of entire spindle is not possible.

- Operational speed and temperature mainly influence the eigenvalues, but the measurement of FRFs when the spindle rotates is quite difficult. 
- Curve fitting or other methods to extract parameters out of the measured input and output data do not always lead to accurate identification of the spindle's dynamic parameters.

Other approaches consist in using operational modal analysis (OMA) instead of experimental modal analysis (EMA) to assess the dynamic stiffness, natural frequencies, damping and identify chatter free cutting conditions in process planning of part machining operations.

The operational modal analysis (OMA) is considered as a powerful tool for dynamic modal parameter identification during machining operation. This approach allows evaluating the machine-tool's modal parameters during machining operations and measuring the change compared to the static modal parameters (at $0 \mathrm{rpm}$ ). This method is simple and safe. It exploits only the output signals without knowing the input excitation to the system, which is the case in most machining operations.

Operational modal analysis approaches are firstly applied to the case when the system is excited by white stationary noise. Next, these approaches are generalized in cases with periodic excitation and non-stationary noise. A general overview of popular categories of the OMA technics will be presented:

- Methods performing auto and cross-correlation of the time-signals and handling the results as impulse response functions (the Natural Excitation Technique or NExT) [22]. Time domain identification methods are then used to extract modal parameters from impulse responses of the system. To mention a few: Least Square Complex Exponential (LSCE) [23], Polyreference Complex Exponential method (PRCE) [24], Ibrahim Time Domain Method (ITD) [25], Single Station Time Domain method [26] and Eigensystem Realization Algorithm (ERA) [27].

- Methods based on discrete-time data models. Examples of such methods are the Auto Regressive Moving Average Vector (ARMAV) [28] and the Auto Regressive Vector Time Series Modelling [29].

- Stochastic subspace methods such as the Canonical Variate and Balance Realization Techniques [30].

- The Maximum Likelihood frequency domain method, which works on auto-and cross-spectrum functions of the response signals [31].

However OMA methods have limitations when applied to practical cases. One limiting constraint of OMA is that the non-measured excitation to the system in operation must be a stochastic white noise. This implies that if harmonic excitations are present in addition to random forces, the standard OMA procedures could not be applied in a straightforward way. The harmonic response components can sometimes be considered as virtual modes in the identification, but when the harmonic excitation frequencies are close to eigenfrequencies the standard OMA approaches may break down.

In Reference [32], three identification algorithms have been adapted from standard methods in order to explicitly take into account the harmonic response components of known frequency. First of all, the author has proposed a modified Least Square Complex Exponential (LSCE) method, which handles as input the auto- and cross-correlation of the response signals to perform OMA in the presence of harmonic excitations. The author has also proposed a modified Ibrahim Time Domain (ITD) method and a modified Eigensystem Realization Algorithm (ERA) method.

For the diagnosis of dynamic cutting performance, we proposed a new tool in signal processing to characterize the modal parameters that vary with speed. It is essential in operation to adjust the stability lobe and thus to select the optimal machining conditions and avoid chattering. In fact, we propose to use the operational modal analysis (OMA) to generate accurate and dynamic stability charts. Such model takes into account the spindle speed dependent parameters and the wears of machine elements and provides an updated stability lobe.

In the present study, a complete procedure for estimating the machine-tool's dynamic modal parameters under operating conditions is developed. The estimated parameters are used to generate the dynamic stability lobe diagram. To reach this goal, an operational modal analysis approach, i.e. the least square complex exponential (LSCE), is employed. To deal with harmonic excitations, we propose to filter out the harmonic part of the signals from the actual response of the system by using the cepstral editing procedure (CEP). This method developed by Randal and Sawalhi [33] is used to remove the discrete frequency components from the measured signals.

The paper is organized as follows: Section 2 presents a theoretical background. In Section 3, the experimental data acquisition and the cutting conditions are exhibited. In Section 4, the results obtained from the operational modal analysis are presented and discussed. Section 5 puts forward the summary and future works.

\section{Theoretical background}

\subsection{Least square complex exponential (LSCE)}

The Least-square complex exponential is a time domain analysis method. It explores the relationship between the Impulse Response Function (IRF) of a Multi Degree of freedom (MDoF) system and its complex poles and residues through a complex exponential. By establishing the analytical links between both systems, we can construct an autoregressive model (AR model whose solution leads to a polynomial with complex roots). Having estimated the roots (thus the natural frequencies and damping ratios), the residues can be derived from the AR model to estimate mode shapes. The IRF can be derived from the inverse Fourier transform of an FRF or from the "random decrement" process [34].

The LSCE method designed with the response function of an MDoF system is given by:

$$
H_{i j}(s)=\sum_{r=1}^{N} \frac{A_{i j}(r)}{s-s_{r}}+\frac{A_{i j}^{*}(r)}{s-s_{r}^{*}}
$$


Or

$$
\begin{aligned}
H_{i j}(s)= & \sum_{r=1}^{2 N} \frac{A_{i j}(r)}{s-s_{r}} \\
& \text { For } \quad r \succ N: A_{i j}(r)=A_{i j}^{*}(r) ; s_{r}=s_{r}^{*}
\end{aligned}
$$

The inverse Laplace transform of this response function is the IRF given as:

$$
h_{i j}(t)=\sum_{r=1}^{2 N} A_{i j}(r) \mathrm{e}^{s_{r} t}
$$

For simplicity, the subscript of the response function $i j$ is omitted from the following analysis. If this IRF is sampled at a series of equal spaced time intervals $k \Delta(k=$ $0,1, \ldots, 2 N)$, then we obtain a series of sampled IRF data:

$$
h(k \Delta)=\sum_{r=1}^{2 N} A_{i j}(r) \mathrm{e}^{s_{r} k \Delta}(k=0,1, \ldots, 2 N)
$$

Or

$$
h_{k}=\sum_{r=1}^{2 N} A_{i j}(r) z_{r}^{k}(k=0,1, \ldots, 2 N) z_{r}^{k}=\mathrm{e}^{s_{r} k \Delta}
$$

All samples are real valued data, although the residues $A_{i j}(r)$ and the roots $s_{r}$ are complex quantities. It is easy to show that all imaginary parts will cancel each other because of the complex conjugates of both $A_{i j}(r)$ and $s_{r}$. The next step is to estimate the roots and residues from the sampled data. Mathematically, this means that $z_{r}$ are the roots of a polynomial with only real coefficients:

$$
\beta_{0}+\beta_{1} z_{r}+\beta_{2} z_{r}^{2}+\ldots+\beta_{2 N-1} z_{r}^{2 N-1}+\beta_{2 N} z_{r}^{2 N}=0
$$

This equation is known as the Prony equation whose coefficients could be estimated from the samples of the IRF data. Since there are $(2 N+1)$ equalities in Equation (5), each one is multiplied with a corresponding coefficient $\beta$ and then all equalities are added together to form the following equation:

$$
\sum_{k=0}^{2 N} \beta_{k} h_{k}=\sum_{k=0}^{2 N} \beta_{k} \sum_{r=1}^{2 N} A_{i j}(r) z_{r}^{k}
$$

Or

$$
\sum_{k=0}^{2 N} \beta_{k} h_{k}=\sum_{r=1}^{2 N} A_{i j}(r) \sum_{k=0}^{2 N} \beta_{k} z_{r}^{k}
$$

The right hand side of Equation (8) becomes zero when $Z_{r}$ is a root of polynomial in Equation (6). This leads to a simple relationship between the coefficients $\beta$ and the IRF samples, namely:

$$
\sum_{k=0}^{2 N} \beta_{k} h_{k}=0
$$

This equation offers a numerical way for estimating the coefficients $\beta$. In Equation (6) we can assign $\beta_{2 N}$ to be equal to one. Taking a set of $2 N$ samples of IRF, one linear equation for $\beta$ is formed in Equation (9). Taking $2 N$ sets of $2 N$ samples of IRF, we obtain $2 N$ linear equations. The coefficients can be estimated through the following linear simultaneous equation:

$$
\begin{aligned}
& {\left[\begin{array}{lllll}
h_{0} & h_{1} & h_{3} & \cdots & h_{2 N-1} \\
h_{1} & h_{2} & h_{3} & \cdots & h_{2 N} \\
\vdots & \vdots & \vdots & \vdots & \vdots \\
h_{2 N-1} & h_{2 N} & h_{2 N+1} & \cdots & h_{4 N-2}
\end{array}\right]\left\{\begin{array}{l}
\beta_{0} \\
\beta_{1} \\
\vdots \\
\beta_{2 N-1}
\end{array}\right\} } \\
&=\left\{\begin{array}{l}
h_{2 N} \\
h_{2 N+1} \\
\vdots \\
h_{4 N-1}
\end{array}\right\}
\end{aligned}
$$

The selection of IRF data samples provides different $h$ elements for each row. Such rows are evenly spaced and sequentially arranged. The number of rows in Equation (10) can exceed the number of $\beta$ coefficients for the leastsquare solutions.

With known $\beta$ coefficients, Equation (6) can be solved to yield the roots $z_{r}$. These roots are related to the complex natural frequencies $s_{r}$ as given in Equation (5). The complex naturel frequencies $s_{r}$ are determined by the undamped natural frequencies $w_{r}$ and damping ratios $\zeta_{r}$ as:

$$
\begin{aligned}
& s_{r}=-\zeta_{r} w_{r}+j \sqrt{1-\zeta_{r}^{2}} w_{r} \\
& s_{r}^{*}=-\zeta_{r} w_{r}-j \sqrt{1-\zeta_{r}^{2}} w_{r}
\end{aligned}
$$

the natural frequency and damping ratio of the $r$ th mode can be derived as:

$$
\begin{aligned}
w_{r} & =\frac{1}{\Delta} \sqrt{\ln z_{r} \ln z_{r}^{*}} \\
\zeta_{r} & =\frac{-\ln \left(z_{r} z_{r}^{*}\right)}{2 w_{r} \Delta}
\end{aligned}
$$

\subsection{Cepstral editing procedure}

The Operational modal analysis is based on the assumption that the input to the structure is stationary with white noise. However, in our case, the structural vibration observed in operation cannot be considered as pure white noise excitation. Such vibrations are induced by a combination of white noise and harmonic excitation, due to the spindle rotation and teeth passages.

To overcome this problem, the deterministic part containing rotating and teeth passage components will be removed from the response signal. Numerous approaches have been used in literature, among which, there is the time-synchronous averaging (TSA) [35]. Other methods have been developed based on the different correlation length of discrete frequency and random signals. One method is the self-adaptive noise cancellation (SANC) [36], which is a modification of ANC (adaptive noise cancellation). The latter procedure has two input signals, a primary signal containing a mixture of two 


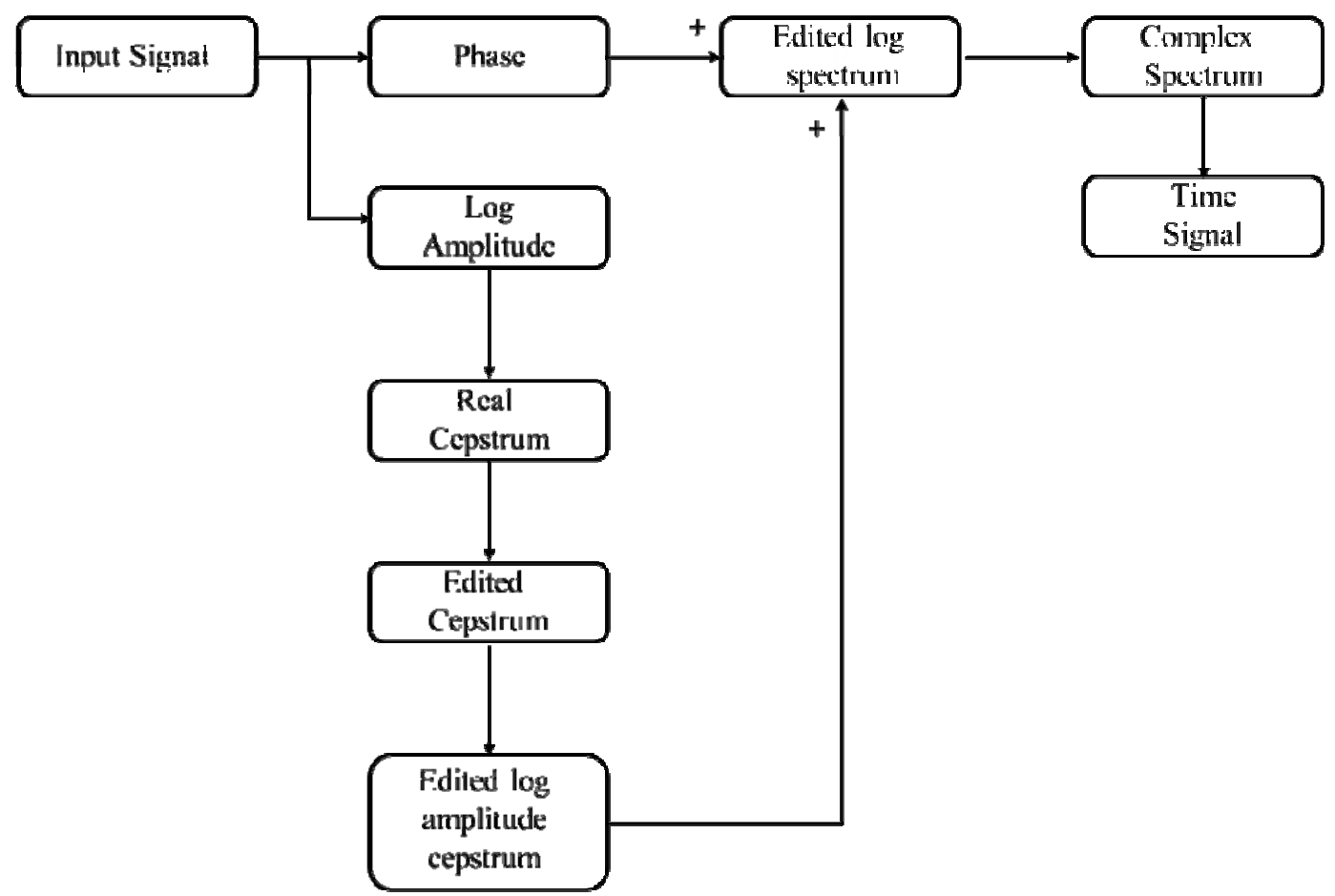

Fig. 1. Schematic diagram of Cepstral Editing Procedure [33].

components to be separated and a reference signal. The discrete random separation (DRS) is another technique developed by Antoni and Randal [37], based on Fourier transform (FFT) processing in the frequency domain.

Earlier, a new method has been developed which gives some advantages when compared with all techniques noted previously. This method is the cepstral editing procedure (CEP) [33]. It doesn't need an order tracking as long as the speed variation is limited. It is based on the cepstrum of the signal that efficiently collects spectral components that are uniformly spaced, that is, both harmonics and modulation sidebands. A schematic diagram of the cepstral editing procedure for removing all deterministic parts (rotation spindle, teeth passages end harmonics) is shown in Figure 1.

\section{Methodology}

\subsection{Experimental set up}

A set of experimental tests was realized by the Huron milling machine (K2X10). This machine can operate at very high speed reaching $28000 \mathrm{rpm}$. Figure 2 shows the schematization of the experimental slot milling setup for studying the OMA based stability prediction. Aluminum samples \# 7075-T6 \# of size [194 mm, $133 \mathrm{~mm}, 50 \mathrm{~mm}$ ] are fixed on the structure. Slot milling operations in different cutting conditions were achieved by 3 flutes micro grain solid carbide end mills.

Three uniaxial accelerometers (PCB352C22) were used to capture the vibrations. Two of them are attached to the free end of the non-rotating part of spindle (spindle support) and oriented along the $X$ and $Y$ directions, in parallel to the machine axis. The third accelerometer is attached to the workpiece. It is oriented along the cutting direction and parallel to the $Y$ axis of machine center. Acceleration signals are acquired with data acquisition system. This system contains a card acquisition \#Data Translation DT 9837\# and a laptop with special software developed by BETAVIB. The sampling frequency selected for all tests is $48 \mathrm{kHz}$. Noting that the DT9837 card uses Delta-Sigma analogous to digital converters (ADCs), that provide anti-aliasing filters based on the clock rate. These filters remove aliasing, which is a condition where high frequency input components erroneously appear as lower frequencies after sampling, reduce noise and improve the accuracy. The card that is equipped with direct connector, contains a signal conditioning.

\subsection{Test configurations}

The test configuration concerns the study of chatter stability prediction for CNC machine in operating condition through operational modal. To analyse the influence of cutting conditions (spindle speed and depth of cut) and the influence of the state of health of tool teeth in chatter stability boundary and modal parameters, several tests were performed in different cutting conditions.

First of all, a tap test was applied on the tool tip in $(X, Y)$ directions to measure the modal parameters of the spindle (including tool and tool holder). The system of measurements consists of:

- A hammer impact as excitation source. 

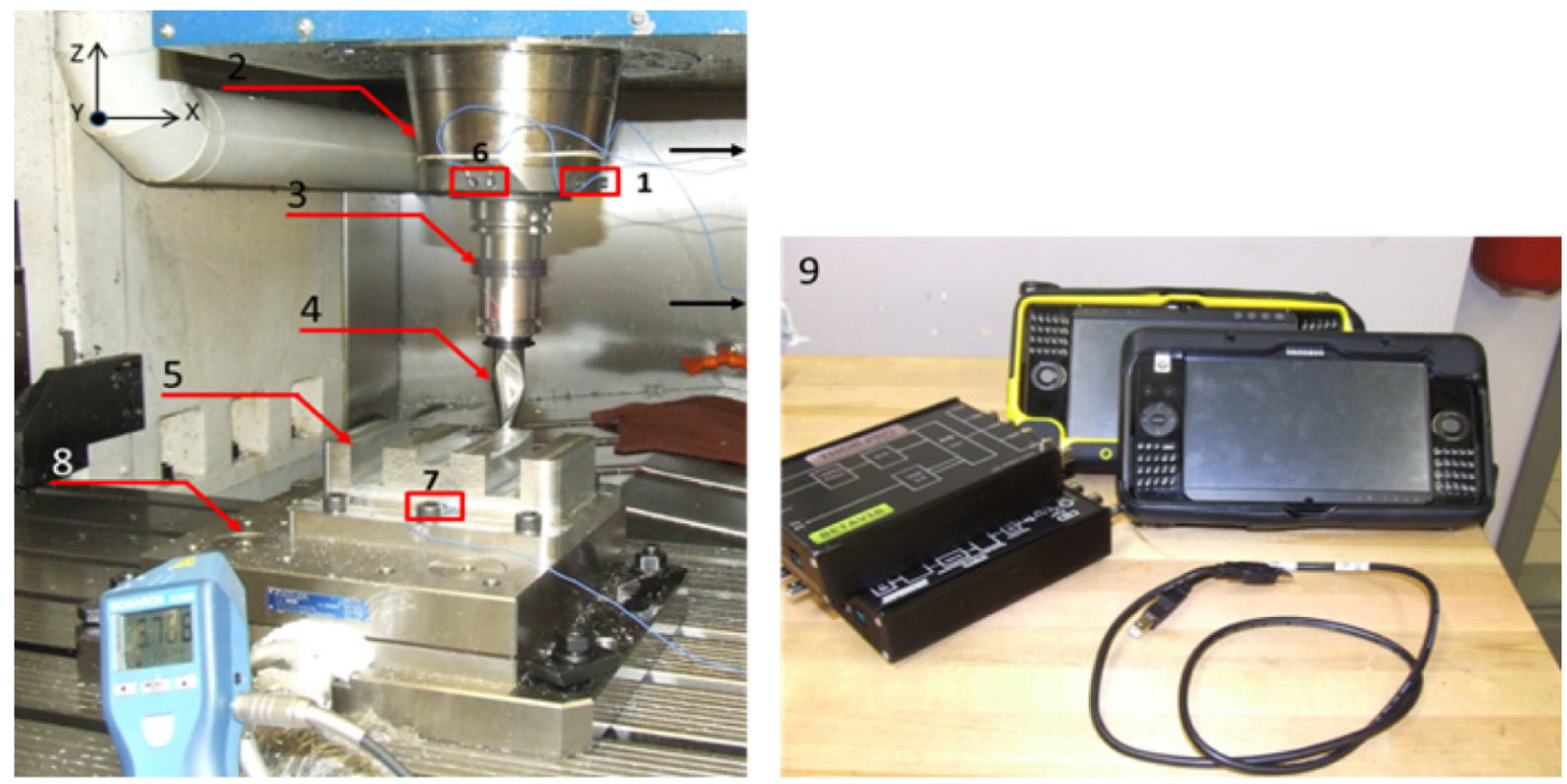

Fig. 2. Experimental slot milling setup (1) accelerometer\#1 (PCB352C22) (2) non-rotating part of the spindle (3) tool-holder (4) three-two- teeth carbide end mill (5) Kistler dynamometer [9255-B] (6) accelerometer\#2 (PCB352C22) (7) accelerometer\#3 (PCB352C22) (8) workpiece AA7075-T6. Arrows indicate the data response to the data acquisition system.

- Accelerometers to measure the vibratory responses.

- Data acquisition system with conditioner and analyzer to collect and analyze the measured data.

The H1 estimation technique was used to estimate the FRF, which is the ratio between the inter-correlation between force and response, and the auto-correlation of force. FRF in $X$ and $Y$ directions with real part, imaginary part, magnitude and coherence are shown in Figure 3.

Secondly, a company of tests (test \#1 to test \#10) were carried out without load (freeload) and with load (in operation) at different spindle speed and depth of cut. Another test (test 11) consists of using worn tools to study the impact of wear on the modal parameter. Therefore, three tests with different tool defect were made in one spindle speed and one depth of cut. The feed in all tests is equal to $0.01 \mathrm{~mm} /$ tooth and the radial depth is equal to $25.4 \mathrm{~mm}$. Table 1 summarizes all cutting tests during the experimental study.

After acquiring the signals in different cutting conditions, we will apply the methodology described in Figure 4 . The following sections show the results as follows.

First of all, we perform a spectral analysis on different signals to know their underlying spectral content. Then we present the different transfer functions obtained after having applied the CPE method. This step is applied to signals without load (without machining) and in operation. Once the transfer functions are estimated, we apply the method of LSCE for extracting modal parameters. The results are displayed in Sections 4.3. In this section we also study the influence of speed on the modal parameters. Finally, we present the stability lobe diagrams estimated from the modal parameters found in the previous sections and that in different machining conditions.

\section{Results and discussion}

\subsection{Spectral analysis}

The power spectral densities of acceleration signals that are acquired from the accelerometers fixed to the free end of the non-rotating part of spindle in $X$ and $Y$ directions are shown in Figure 5. Such signals are acquired without load (without machining) in five different spindle speeds that are $3000 \mathrm{rpm}, 5000 \mathrm{rpm}, 8000 \mathrm{rpm}$, $10000 \mathrm{rpm}$ and $12000 \mathrm{rpm}$.

The Spectra of signals with different spindle speeds are similar for both $X$ and $Y$ directions. They highlight dominant peaks that correspond to spindle rotation frequency and its harmonics. These spectra show also the machine structure dynamic through the amplifications presented in some zone of spectra. The zones of resonance are clearly distinguished in $Y$ direction, which correspond to cutting direction.

Operational analysis assumes that the input signal is a white noise sequence. The violation of this assumption by the presence of harmonic components in the excitation, will lead to extra peaks in the power spectra that are not evidence of structural modes. Clearly, these extra peaks need to be eliminated and distinguished from the true structural modes. The methodology described above (Fig. 1) allows separating between non-structural modes (harmonic components) and structural modes and keeps only the latter. 

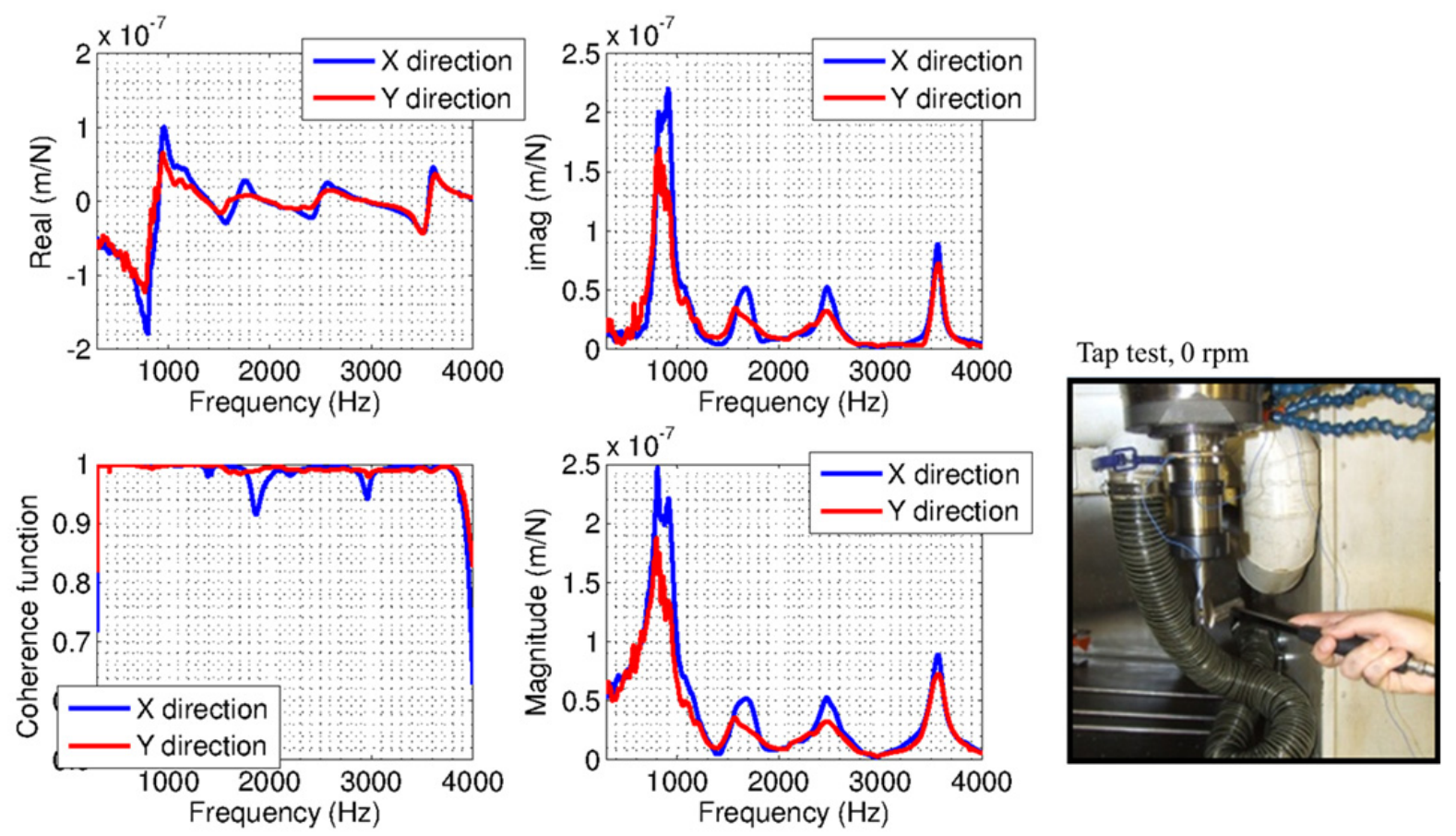

Fig. 3. Real, imaginary, magnitude and coherence parts of the machine-tool response function in $X$ and $Y$ direction for 0 rpm spindle speed (Tap test results).

Table 1. Summary of the cutting conditions.

\begin{tabular}{cccc}
\hline Test \# & Cutting depth $(\mathrm{mm})$ & Spindle speed $(\mathrm{Rpm})$ & Comments \\
\hline 1 & & 3000 & $/$ \\
2 & & 5000 & $/$ \\
3 & Without load & 8000 & $/$ \\
4 & & 10000 & $/$ \\
5 & & 12000 & New tool \\
6 & 2 and 6 & 3000 & New tool \\
7 & 3 and 6 & 5000 & New tool \\
8 & 2 and 6 & 8000 & New tool \\
9 & 3 and 6 & 10000 & New tool \\
10 & 2 and 5 & 12000 &
\end{tabular}

In the next section, the methodology is applied to acceleration signals for estimating the frequency response functions.

\subsection{Frequency response function estimation}

\subsubsection{Without load (without milling)}

The chatter stability of the tool depends on the dynamic behaviour of the spindle system, which is often expressed as the frequency response function (FRF) at the tool tip. In other words, the frequency response function is a key variable for determining the stability limit [3].

Applying the PCE procedure to acceleration signals allows getting the frequency response functions (FRFs) for any cutting condition and for different spindle speeds. Figures $6 \mathrm{a}$ and $6 \mathrm{~b}$ present five frequency response func- tions estimated in free load milling and one in static condition ( $0 \mathrm{rpm})$ for both $X$ and $Y$ directions respectively. The representation of the variations of FRFs for small interval of spindle speed can be interpreted as a Campbell diagram and each constant speed vertical layer represents the FRF.

We note a similarity in waveform between the response function estimated in static condition $(0 \mathrm{rpm})$ and the response functions estimated in free load dynamic conditions. We note also the appearance of other resonance frequencies in dynamic condition. In fact, dynamic effects due to high rotational speed and elastic deformations, such as gyroscopic coupling and spin softening, have significant influences on spindle behaviour.

In a non-rotating spindle ( $0 \mathrm{rpm})$, two bending shapes are associated with a bending frequency (ex. Point w), due to the rotor axial-symmetry. When the spindle rotates, the frequencies associated with these two bending shapes 


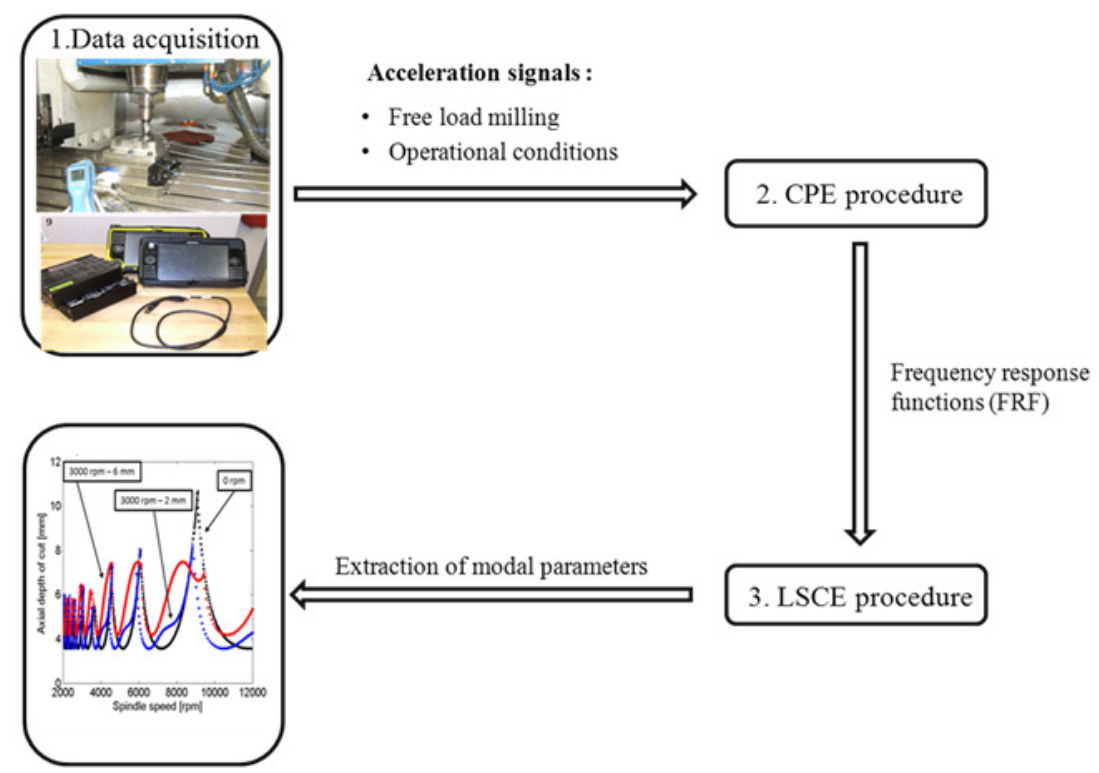

4. Analytical stability lobe diagrams

Fig. 4. Methodology of operational modal analysis, applied on vibration signals.
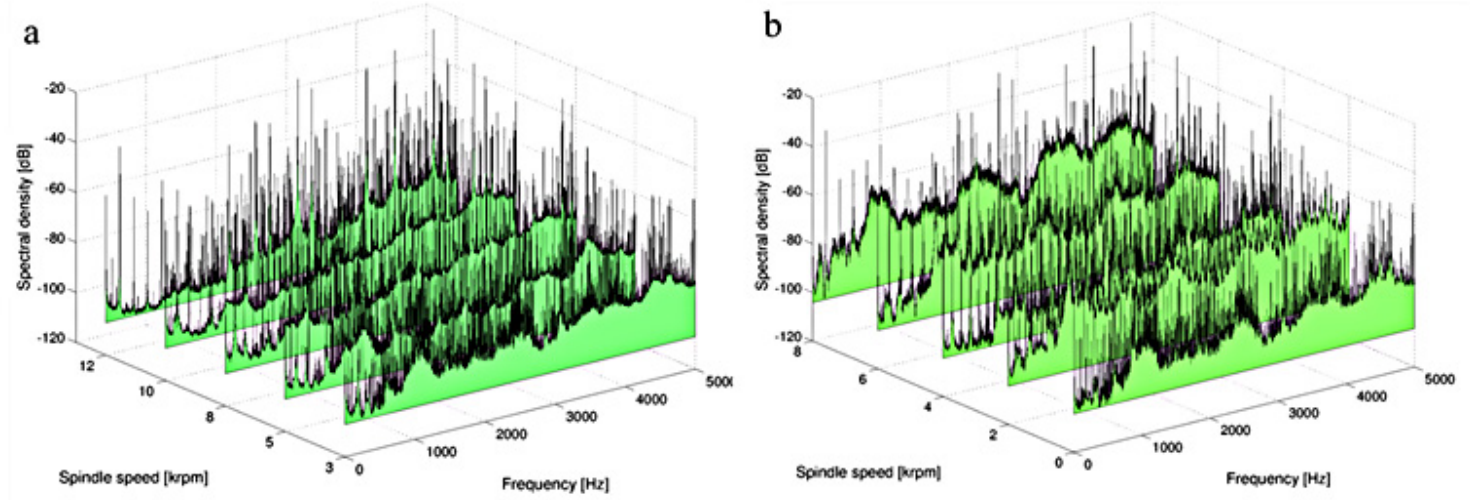

Fig. 5. Power spectral density of acceleration signals in (a) $X$ and (b ) $Y$ directions for different spindle speeds. Accelerometers signals presented in these figures are acquired without load in different spindle speeds $(3,5,8,10$ and 12$) \mathrm{krpm}$.

a

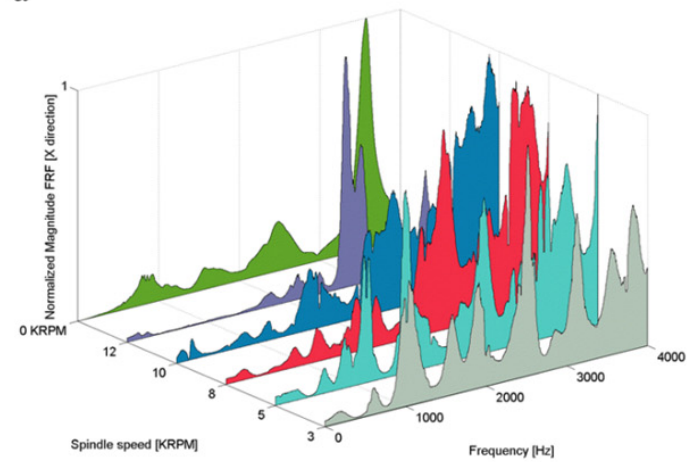

b

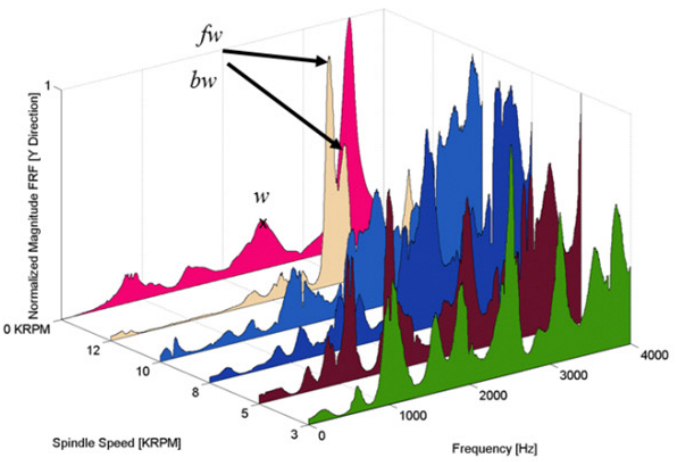

Fig. 6. Frequency response functions estimated by CPE procedure for acceleration signals acquired in free load milling. (a) Frequency response functions estimated in $X$ direction and for spindle speeds of $(0 \mathrm{rpm}, 3000 \mathrm{rpm}, 5000 \mathrm{rpm}, 8000 \mathrm{rpm}$, $10000 \mathrm{rpm}$ and $12000 \mathrm{rpm}$ ). (b) Frequency response functions estimated in $Y$ direction and for spindle speeds of (0 rpm, $3000 \mathrm{rpm}, 5000 \mathrm{rpm}, 8000 \mathrm{rpm}, 10000 \mathrm{rpm}$ and $12000 \mathrm{rpm})$. 

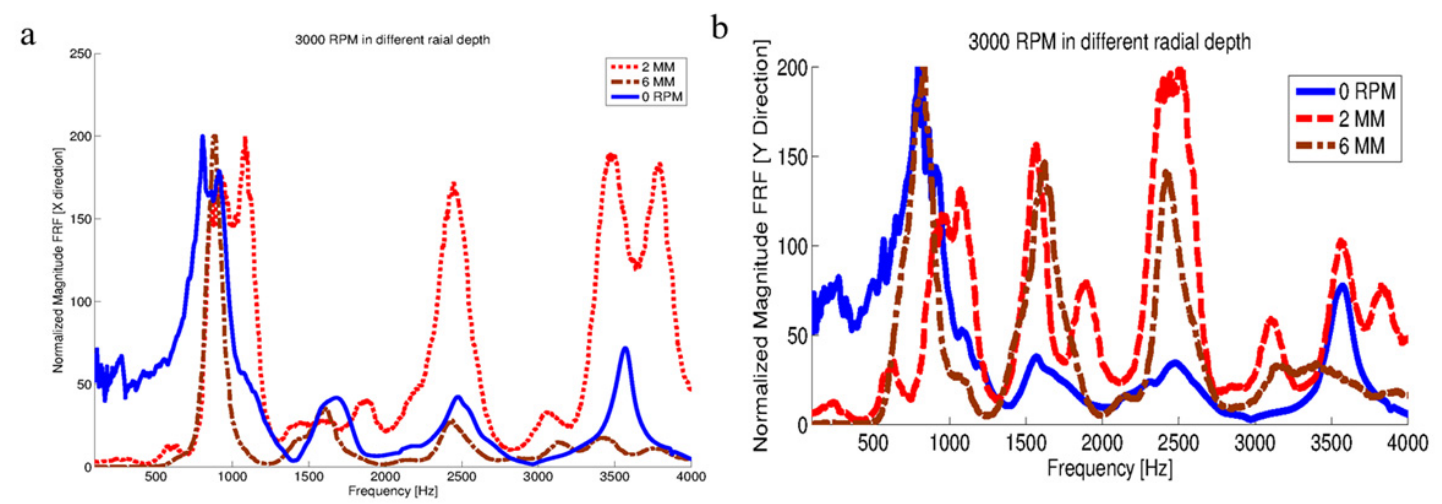

Fig. 7. Frequency response functions estimated by CPE procedure for acceleration signals acquired in operational condition (milling operation) (a) FRFs estimated in $X$ direction: solid blue line represents FRF of signal acquired in static condition $(0 \mathrm{rpm})$ by tap test, dash red line represents FRF of signal acquired at spindle speed of $3000 \mathrm{rpm}$ and depth of cut of $2 \mathrm{~mm}$, dash-dot brown line represents FRF of signal acquired at spindle speed of $3000 \mathrm{rpm}$ and depth of cut of $6 \mathrm{~mm}$. (b) comments of (a) sub-figure but in $Y$ direction.
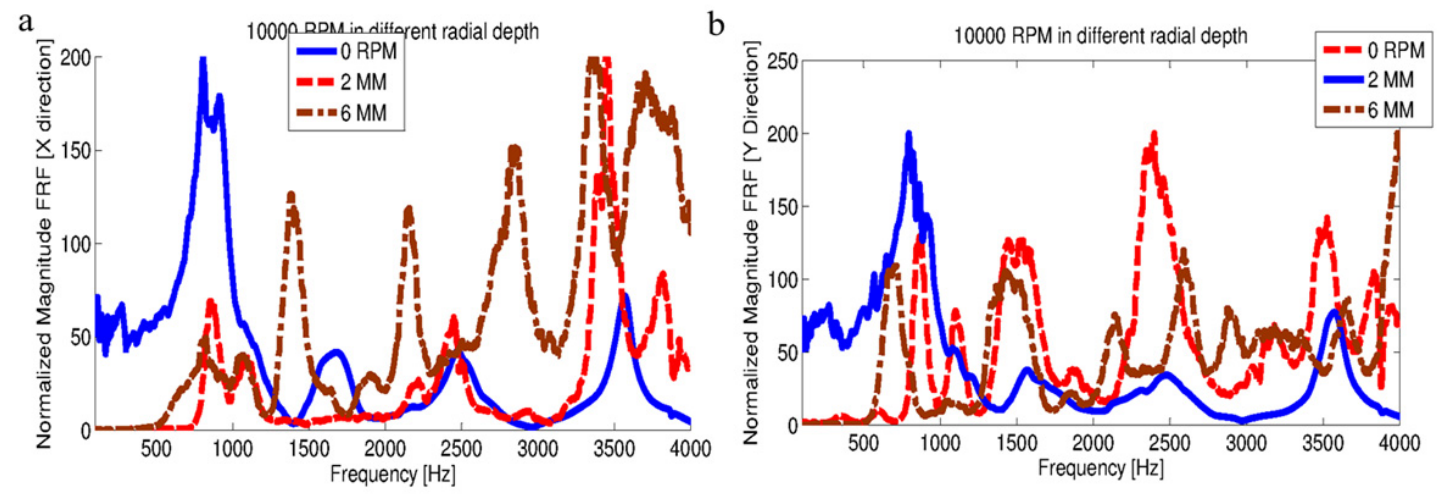

Fig. 8. Frequency response functions estimated by CPE procedure for acceleration signals acquired in operational condition (milling operation). (a) FRFs estimated in $X$ direction: solid blue line represents FRF of signal acquired in static condition $(0 \mathrm{rpm})$ by tap test, dash red line represents FRF of signal acquired at spindle speed of $10000 \mathrm{rpm}$ and depth of cut of $2 \mathrm{~mm}$, dash-dot brown line represents FRF of signal acquired at spindle speed of $10000 \mathrm{rpm}$ and depth of cut of $6 \mathrm{~mm}$. (b) comments of (a) sub-figure but in $Y$ direction.

move apart, one above and one below the rest value (bw and $f(w)$, as a function of spindle speed. These two different solutions are called forward and backward whirls in rotor dynamics literature [7].

\subsubsection{With load (milling operation)}

Figures 7 and 8 show the frequency response functions estimated by Cepstral Editing Procedure for acceleration signals acquired at different cutting conditions (spindle speeds: 3000 and $10000 \mathrm{rpm}$, depth of cut: 2, $6 \mathrm{~mm}$ ) and for two directions $X$ and $Y$. The dynamic FRFs estimated by CPE are compared with static FRF estimated by tap test.

The FRFs estimated in operating conditions correspond to those found in static conditions. Four main predominant modes are observed on FRFs which are around 800-1570-2470 and $3570 \mathrm{~Hz}$, accompanied by other sec- ondary modes. The main dynamic modes (modes estimated in operating conditions) are more shifted compared with static modes, and this is due to high rotational speed and gyroscopic effect.

The contribution of each mode is not correctly estimated and it does not correspond to real mode contribution, so the amplitude of each mode is different from that in static case. In this work, the methodology is limited to the estimation of modal damping and natural frequency, whereas modal residues are not well identified and this does not cause a problem for the rest of the study. The modal mass identified in the impulse test is used to predict the stability boundary.

The importance of the proposed methodology resides in the identification of FRF despite the presence of harmonic excitations. In fact, in many practical cases, harmonic excitations are often present in addition to the white noise. If the harmonic frequency is close to structural frequencies, such identification fails. 


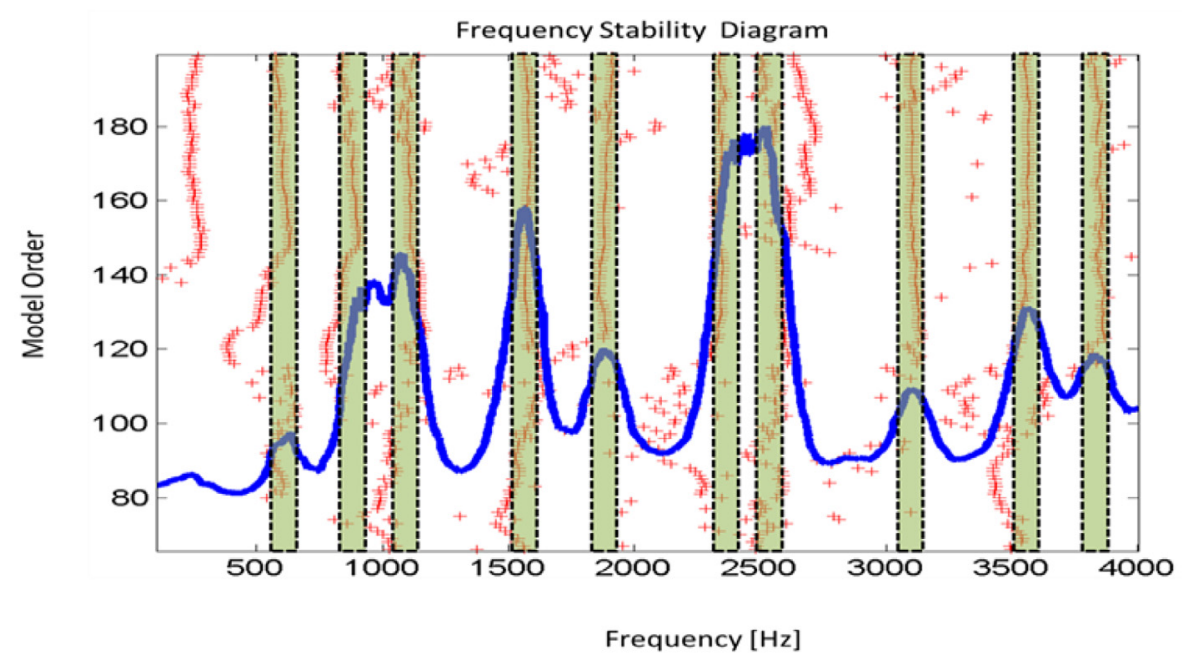

Fig. 9. Frequency stability diagram using Least Square Complex Exponential method (LSCE). The treated acceleration signal is from test \#6 in Table 1 (3000 rpm, $2 \mathrm{~mm})$. The blue curve presents the frequency response function estimated by CPE procedure. The red cross-symbols $(+)$ present the potential natural frequencies in the $x$ direction. The dashed lines present the interval confidence of $95 \%$ for the selection of natural frequencies, in this Figure 10 natural frequencies are selected with $95 \%$ of confidence.
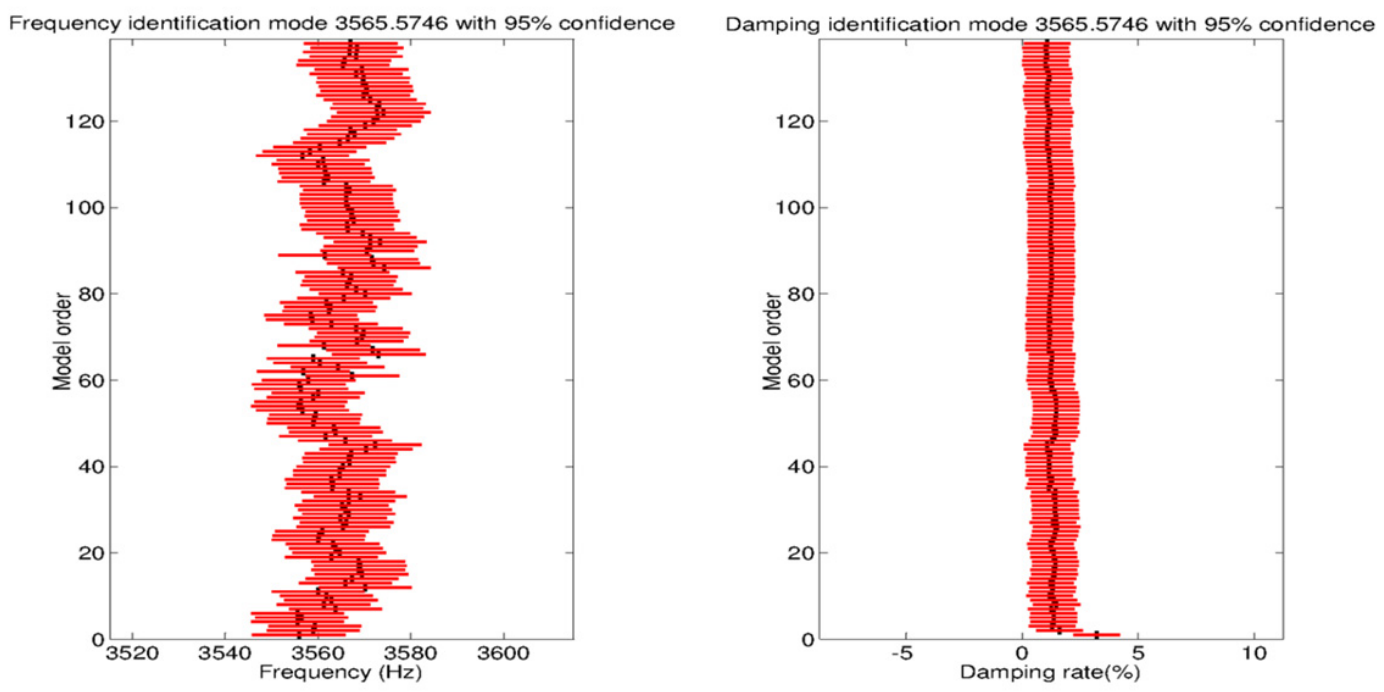

Fig. 10. Natural frequency and damping ratio stability diagrams for the frequency (9th mode) 3565 Hz observed in Figure 8 . The values are presented with confidence interval of $95 \%$.

\subsection{Modal parameter extraction (frequency and damping)}

The previous section explained the algorithm for estimating the system natural frequencies, through operational modal analysis. Figure 9 presents the results of the operational modal analysis using the LSCE method, with $3000 \mathrm{rpm}$ spindle speed and a cutting depth of $2 \mathrm{~mm}$. In this figure, the $x$-axis represents the system's potentialnatural frequencies while the y-axis is the model order which is referred to the number of natural frequencies found when running the algorithm. For example, with a 200-order model, the LSCE algorithm will generate
200 possible solutions for the system, and these solutions are between $0 \mathrm{~Hz}$ and half the sampling frequency.

Figure 9 shows the frequency stability diagram, that presents the frequency solutions according to the model order. The frequencies found by the LSCE algorithm present the natural frequencies, and the problem of harmonic excitations is eliminated by the proposed methodology. The fluctuation of natural frequencies according to the order model is due to the time-varying system and the studied mechanism.

Figure 9 presents also the selected bounds that allow estimating the natural frequencies. Ten intervals are selected which correspond to ten natural frequencies. 


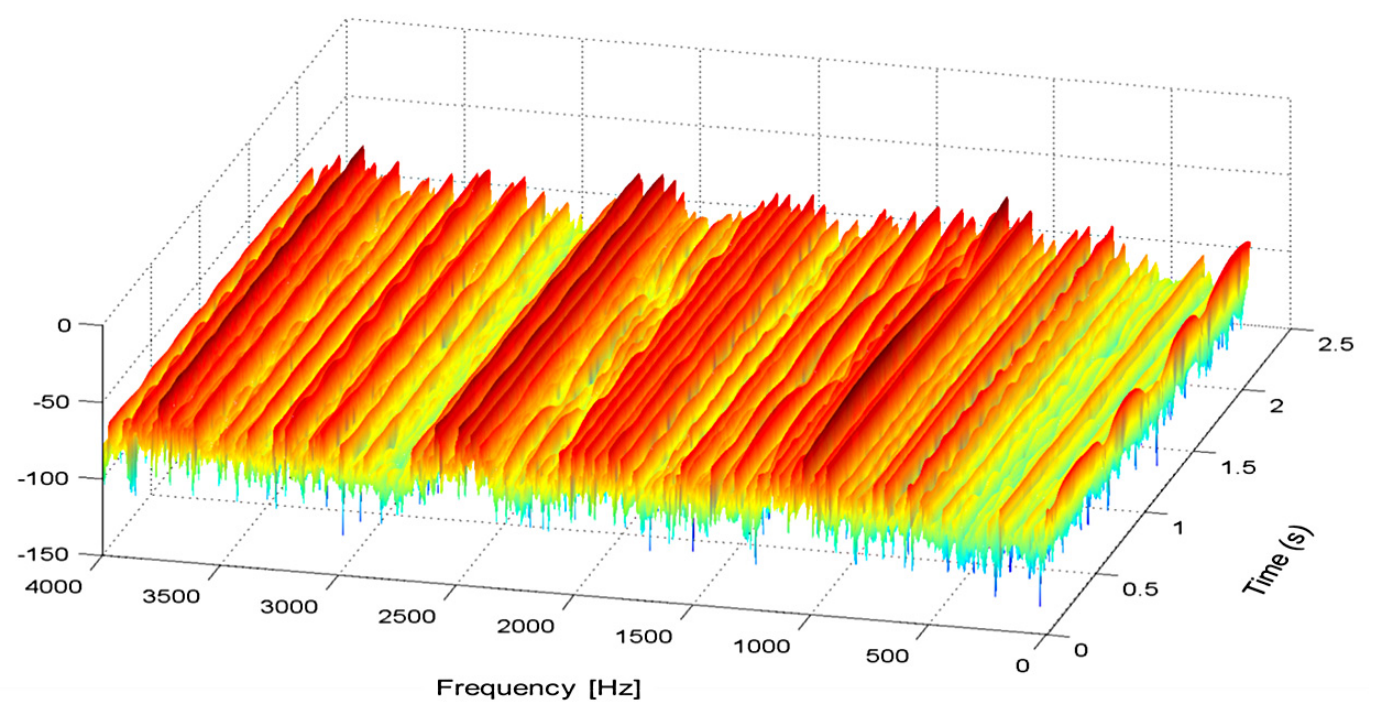

Fig. 11. Short-time Fourier transform (STFT).

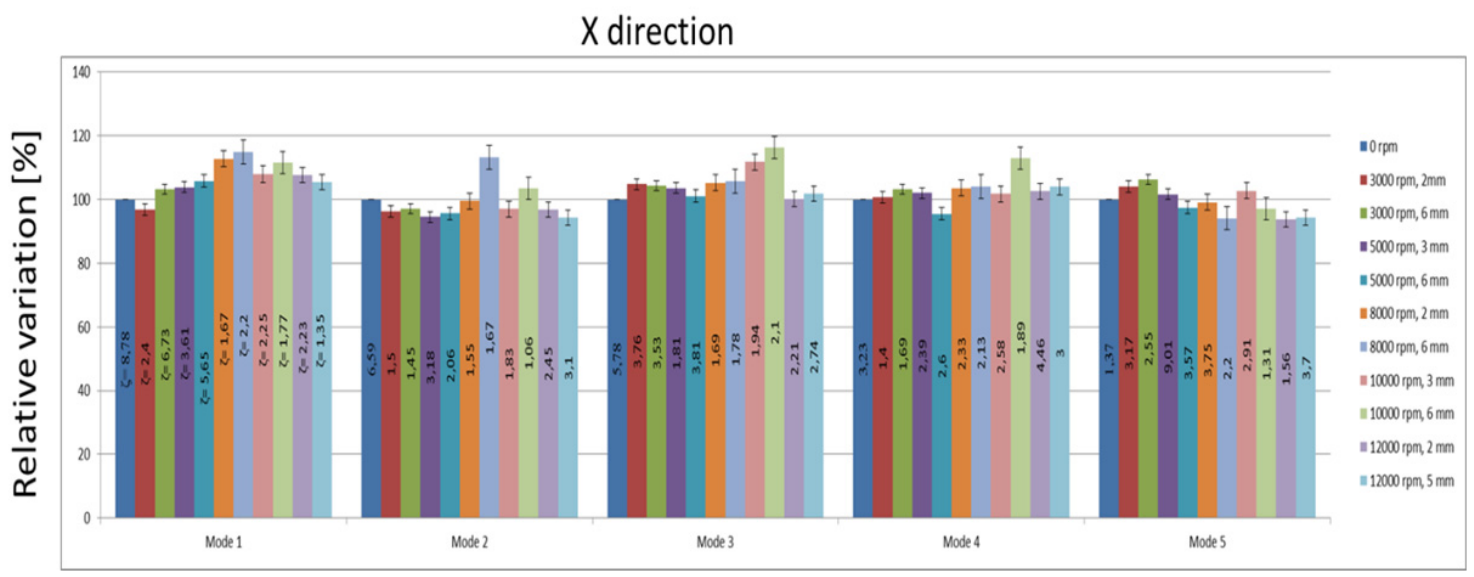

Fig. 12. Variation of the natural frequencies of the machine-tool system when machining at different spindle speed and depth of cut in X direction. Each graph presents the frequencies relative variation of an operational modal analysis method. (Relative variation $=\left(\left(w_{n-\text { machining }}-w_{n-0} \mathrm{rpm}\right) / w_{n-0} \mathrm{rpm}\right)$.

Compared to the STFT in Figure 11, which is computed on the same signal that generates Figure 9, it is clear that the proposed methodology outperforms in term of revealing the natural frequencies.

The changes in natural frequency and damping rate of the 9 th order $(3565 \mathrm{~Hz}$, Fig. 9) are plotted in Figure 10 with $95 \%$ confidence interval. As it is logically seen when the order changes, the natural frequency changes and fluctuates around an average value. These average values that present natural frequencies will be used to estimate the stability bounds. The damping identification only gives an approximate range of values.

\subsection{Speed dependent dynamic modal parameters}

In this section, the influence of the spindle speed with or without milling on dynamic modal parameters is treated. The results are summarized in Table 2 and Figure 12.

\subsubsection{Influence of the spindle speed on dynamic modal parameters (without milling)}

Table 2 shows the dynamic modal parameters (natural frequency and damping ratio) depending on the spindle speed in free load milling condition. This ascertainment is valid for both cutting directions. In dynamic condition, almost all modes obtained in static condition by tap test procedure are produced as well as other secondary modes.

Note also that there are no frequencies corresponding to the spindle speed or its harmonics, and this proves the accuracy and reliability of our proposed methodology toward harmonic excitations.

The variations in natural frequencies are significant and could reach $25 \%$ to $30 \%$ compared to the results 
Table 2. Frequencies and associated damping identified by LSCE algorithm for acceleration signals acquired in $X$ and $Y$ directions and in free milling conditions (without milling).

\begin{tabular}{|c|c|c|c|c|c|c|c|c|c|c|c|c|}
\hline \multirow{2}{*}{$\begin{array}{l}\text { Modes } X Y \\
\text { direction }\end{array}$} & \multicolumn{2}{|c|}{$\begin{array}{l}\text { Tap test } \\
0 \mathrm{rpm}\end{array}$} & \multicolumn{2}{|c|}{$\begin{array}{l}\text { Test \# } 1 \\
3 \mathrm{Krpm}\end{array}$} & \multicolumn{2}{|c|}{$\begin{array}{l}\text { Test \# } 2 \\
5 \mathrm{Krpm}\end{array}$} & \multicolumn{2}{|c|}{$\begin{array}{c}\text { Test \# } 3 \\
8 \mathrm{Krpm}\end{array}$} & \multicolumn{2}{|c|}{$\begin{array}{l}\text { Test \# } 4 \\
10 \mathrm{Krpm}\end{array}$} & \multicolumn{2}{|c|}{$\begin{array}{l}\text { Test \# } 5 \\
10 \mathrm{Krpm}\end{array}$} \\
\hline & $\mathrm{X}$ & $\mathrm{Y}$ & $\mathrm{X}$ & $\mathrm{Y}$ & $\mathrm{X}$ & $\mathrm{Y}$ & $\mathrm{X}$ & $\mathrm{Y}$ & $\mathrm{X}$ & $\mathrm{Y}$ & $\mathrm{X}$ & $\mathrm{Y}$ \\
\hline $1 w_{n}(\mathrm{~Hz})$ & 807.5 & 793 & \multirow{2}{*}{\multicolumn{2}{|c|}{-}} & - & 837.5 & - & 849 & 880.4 & 866 & \multirow{2}{*}{\multicolumn{2}{|c|}{-}} \\
\hline$\zeta(\%)$ & 8.78 & 11 & & & & 1.46 & & 1.89 & 0.98 & 1.47 & & \\
\hline $2 w_{n}(\mathrm{~Hz})$ & 916 & 912 & 995 & - & 1094.1 & 1087 & 1096 & - & 1148 & 1130 & \multirow{2}{*}{\multicolumn{2}{|c|}{-}} \\
\hline$\zeta(\%)$ & 5.78 & 8.56 & 1.1 & & 2 & 1.47 & 2.05 & & 1.93 & 1.22 & & \\
\hline $3 w_{n}(\mathrm{~Hz})$ & 1071 & 1085 & 1066 & 1017 & 1167.8 & 1166 & - & 1122 & - & & \multirow{2}{*}{\multicolumn{2}{|c|}{-}} \\
\hline$\zeta(\%)$ & 3.23 & 3.92 & 3.33 & 3.68 & 1.88 & 1.45 & & 1.59 & & & & \\
\hline $4 w_{n}(\mathrm{~Hz})$ & 1677 & 1573 & - & 1567 & 1599.3 & 1604 & 1860 & 1614 & 1700 & 1763 & 1791 & 1765 \\
\hline$\zeta(\%)$ & 1.37 & 1.59 & & 4.32 & 1.37 & 1.66 & 2.16 & 2.58 & 1.11 & 1.1 & 1.21 & 1.87 \\
\hline $5 w_{n}(\mathrm{~Hz})$ & 2479 & 2474 & 2512.6 & 2546 & 2224.3 & 2592 & 2416 & 2391 & - & - & 2114 & 2384 \\
\hline$\zeta(\%)$ & 2.25 & 2.6 & 1.31 & 3.68 & 1.38 & 1.59 & 2.2 & 2.3 & & & 1.41 & 1.28 \\
\hline $6 w_{n}(\mathrm{~Hz})$ & \multirow{2}{*}{\multicolumn{2}{|c|}{-}} & 3104.9 & 3118 & 2978.3 & - & 2733 & 2715 & - & 2705 & 2684 & $\overline{2696}$ \\
\hline$\zeta(\%)$ & & & 1.32 & 1.27 & 1.38 & & 2.09 & 1.8 & & 2.16 & 1.73 & 1.84 \\
\hline $7 w_{n}(\mathrm{~Hz})$ & 3564 & 3574 & 3398.48 & 3562 & 3328.3 & - & 3486 & - & 3373 & - & 2949 & 2936 \\
\hline$\zeta(\%)$ & 1.56 & 1.8 & 1.54 & 1.28 & 6.35 & & 2.3 & & 2.29 & & 1.6 & 1.81 \\
\hline $8 w_{n}(\mathrm{~Hz})$ & \multirow{2}{*}{\multicolumn{2}{|c|}{-}} & \multirow{2}{*}{\multicolumn{2}{|c|}{-}} & 3373.9 & 2592 & 3569 & 3539 & 3472 & 3435 & 34.2 & - \\
\hline$\zeta(\%)$ & & & & & 2.01 & 1.59 & 2.88 & 1.77 & 1.26 & 2.01 & 1.92 & \\
\hline $9 w_{n}(\mathrm{~Hz})$ & \multirow{2}{*}{\multicolumn{2}{|c|}{-}} & 3807.35 & 3822.8 & - & 3615 & 3796 & - & 3859 & 3859 & 3695 & 3684 \\
\hline$\zeta(\%)$ & & & 3.3 & 1.29 & & 1.53 & 1.79 & & 1.61 & 1.43 & 1.58 & 1.56 \\
\hline
\end{tabular}

issued from tap test. There is no rule about the variation of this parameter, it can increase as it may decrease depending on the spindle speed and studied process. This conclusion is in concordance with the experimental results reported by Gagnol et al. [7] and Zaghbani et al. [8] for non-machining conducted at $0 \mathrm{rpm}$ and at variable spindle speed. Regarding the damping ratio, it has low variations as function of spindle speed. The variations in modal parameters, natural frequency or damping ratio, are due to numerous effects like: the viscous damping force, the centrifuge stiffening and the gyroscopic force on the spindle rotor.

\subsubsection{Influence of the spindle revolution speed on dynamic modal parameters (with milling)}

Figure 12 represents the variations of natural frequencies of the machine-tool system when machining at different spindle speed and different depth of cut in $X$-direction. Each graph presents the frequencies relative variation of an operational modal analysis method with $95 \%$ of confidence.

Five modes are dominant within the interest range 0$4000 \mathrm{~Hz}$. The dynamic modal parameters of the machine tools structure during machining were identified by OMA methods and compared with the results of conventional tap test. It can be seen that the natural frequencies of the LSCE method are different from those of EMA method (experimental modal analysis). An $18 \%$ relative variation $\left(\left(w_{n-\text { machining }}-w_{n-0} \mathrm{rpm}\right) / w_{n-0} \mathrm{rpm}\right)$ can be observed in mode 1 at $8000 \mathrm{rpm}$ spindle speed and $6 \mathrm{~mm}$ of cutting depth. When it comes to damping, the results of the OMA method don't match well, however both are higher or lower than the EMA results. The results indicate that the dynamic properties of the machine tool structure under operations vary from the results of static impact test.

\subsection{Stability analysis of the milling system}

To visualize the influence of the variation of modal parameters on the stability lobe diagrams, the lobes were plotted for four different cases (different spindle speed) in free milling operations (Fig. 13) and milling operations.

Figure 12 presents the stability lobe diagrams computed with different modal parameters estimated at $0 \mathrm{rpm}$ (Fig. 13a) and at different free milling conditions: at $3000 \mathrm{rpm}, 5000 \mathrm{rpm}$ and $1000 \mathrm{rpm}$. It is clear that the stability limits are significantly altered by spindle speed. The stability limit or the minimum axial depth of cut is around $4 \mathrm{~mm}$ in $0 \mathrm{rpm}$ test; this value is increased to be around $6 \mathrm{~mm}$ at $3000 \mathrm{rpm}$, to be more than $6 \mathrm{~mm}$ at $10000 \mathrm{rpm}$ and to be slowly more than $4 \mathrm{~mm}$ at $5000 \mathrm{rpm}$. This means that some conditions that are found to be stable with the parameters estimated in static conditions (0 rpm) could be unstable in free-dynamic conditions (without milling) especially when spindle speed increases.

The observations noted in free milling are also true with milling conditions as shown in Figure 13. This figure represents the stability lobes diagrams of different spindle speeds and axial depth of cut $(3000 \mathrm{rpm}-2 \mathrm{~mm}$ and $8000 \mathrm{rpm}-6 \mathrm{~mm})$.

The variation in spindle speed and axial depth of cut leads to a variation of the stability limit. It can be observed that the stability lobes in Figure 14a $(0 \mathrm{rpm})$ and in Figure 14a (3000 rpm-2 mm) are very similar, while the stability lobes in Figure 14a, (3000 rpm-6 mm) deviate more and are few tenths of a millimeter upper than the two others. Regarding the second case (Fig. 14b), the 

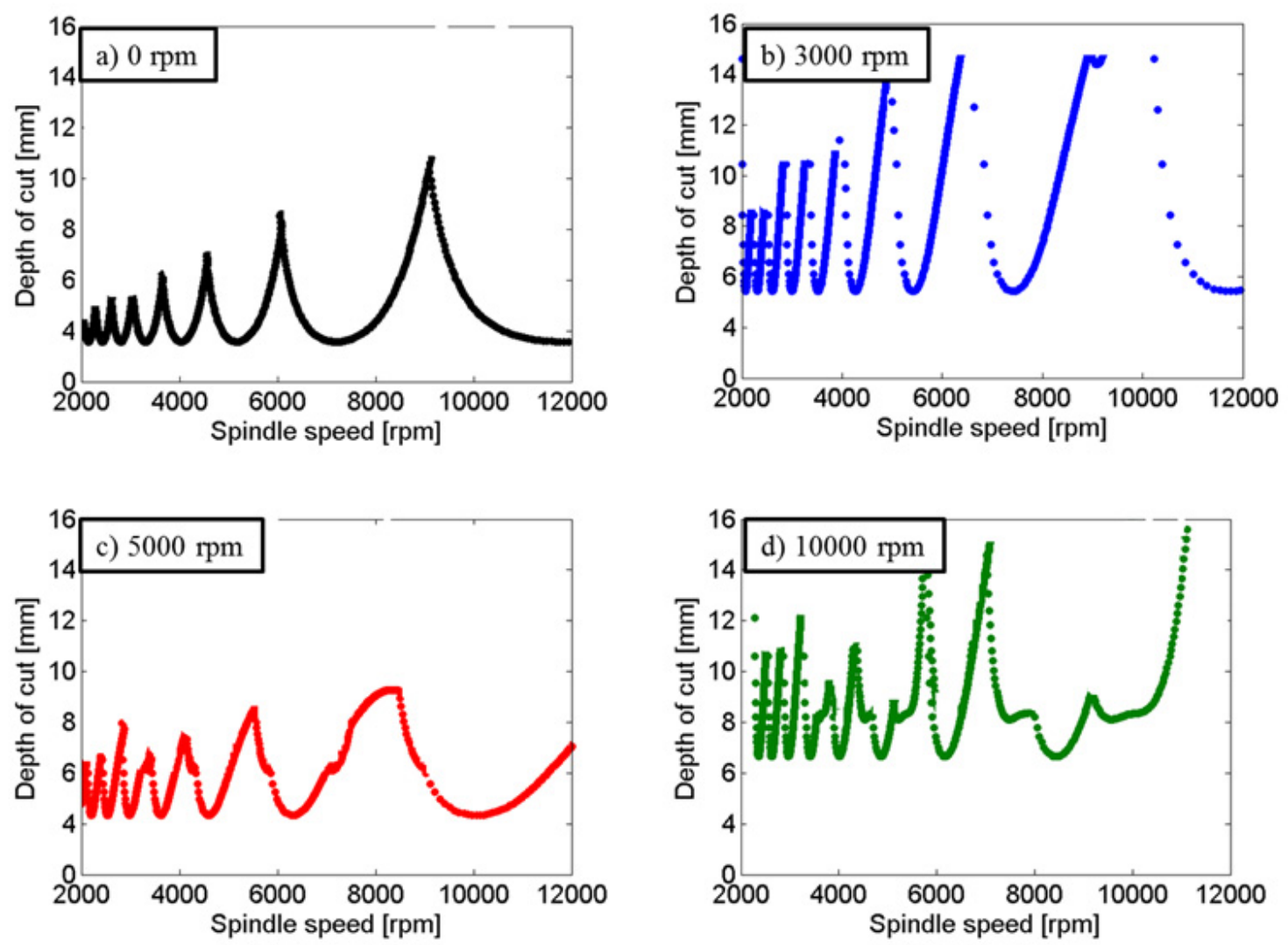

Fig. 13. Analytical stability lobe diagrams generated from different modal parameters in free milling operations, lobes (a) from $0 \mathrm{rpm}$ impact test, lobes (b) from modal parameters estimated at $3000 \mathrm{rpm}$, lobes (c) from modal parameters estimated at $5000 \mathrm{rpm}$, lobes (d) from modal parameters estimated at $8000 \mathrm{rpm}$.

a)

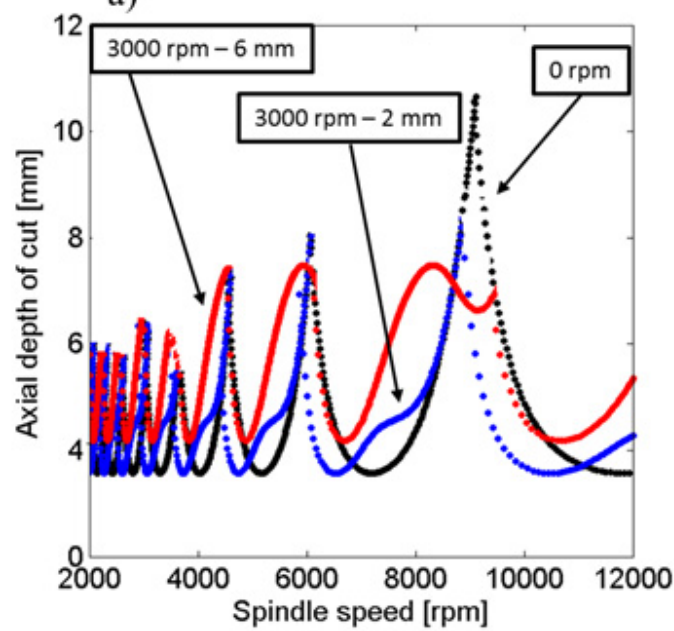

b)

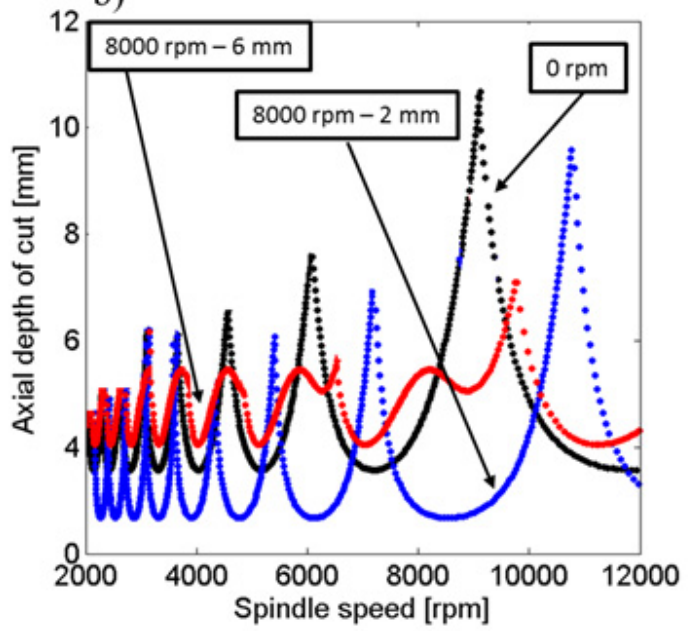

Fig. 14. Analytical stability lobe diagrams generated from different modal parameters in different milling conditions (a) 0 rpm: lobes estimated in tap test, $3000 \mathrm{rpm}-2 \mathrm{~mm}$ : lobes estimated from modal parameters at spindle speed of $3000 \mathrm{rpm}$ and $2 \mathrm{~mm}$ of depth of cut, $3000 \mathrm{rpm}-6 \mathrm{~mm}$ : lobes estimated from modal parameters at spindle speed of $3000 \mathrm{rpm}$ and $2 \mathrm{~mm}$ of depth of cut (b) lobes estimated in $0 \mathrm{rpm}, 8000 \mathrm{rpm}-2 \mathrm{~mm}$ and $8000 \mathrm{rpm}-6 \mathrm{~mm}$. 
stability lobes move upwards or downwards creating other stability areas.

\section{Conclusions}

This paper presents a new procedure based on the LSCE algorithm and CPE method. The proposed methodology has been introduced to identify modal parameters from measurements in operation conditions and to allow the adjustment of stability lobes diagram.

The originality of our proposed approach lies in solving the harmonic problems. This implies a good estimation of the transfer function and therefore the modal parameters. On the other side, the approach allows to identify the stability lobes diagram in operating condition.

To validate our approach, different slot milling tests are realized in free and operating conditions. The first step of our methodology consists of applying the CPE algorithm to estimate the transfer functions in dynamic conditions. Then, the modal parameters (natural frequencies and damping ratios) are estimated by Last square complex exponential method (LSCE) with $95 \%$ of bound confidence. Finally, the estimated dynamic modal parameters are used to predict the tool-spindle based chatter instability. CPE algorithm is also proposed in order to eliminate the so-called 'virtual modes' that correspond to the harmonic excitation.

The results obtained in operating conditions are compared to those obtained in static condition by tap test. Results show a similarity in form between the response function estimated in static condition $(0 \mathrm{rpm})$ and the response functions estimated in free load (without milling) or in load (with milling) dynamic conditions. We noted also the appearance of other resonance frequencies in dynamic condition. Natural frequencies and damping ratios depend of the milling condition. In fact, dynamic effects due to high rotational speed and elastic deformations, such as gyroscopic coupling and spin softening, have significant influence on spindle behaviour, which affect the modal parameters.

The proposed methodology allows adjusting with accuracy the stability limit, which aid in the selection of the optimum cutting parameters.

Acknowledgements. Funding for this project was provided by a grant from the "Région Rhone-Alpes". Special acknowledgements are given to Marc Thomas and Bechir Badri from DYNAMO laboratory of ETS for their interesting comments and experimental assistances.

\section{References}

[1] S.A. Tobias, Vibraciones en Maquinas-Herramientas, URMO, Spain, 1961

[2] J. Tlusty, M. Polacek, The stability of machine tools against self-excited vibrations in machining, ASME Int. Res. Prod. 1 (1963) 465-474
[3] Y. Altintas, Manufacturing Automation - Metal Cutting Mechanics, Machine Tool Vibrations, and CNC Design, Cambridge University Press, 2000

[4] Y. Altintas, M. Weck, Chatter Stability of Metal Cutting and Grinding, CIRP Ann. Manufact. Technol. 53 (2004) 619-642

[5] P. Palpandian, R. Prabhu, S. Satish Babu, Stability Lobe Diagram for High Speed Machining Process: Comparison of Experimental and Analytical Methods-Review, Int. J. Innivative Res. In Sinecen Eng. And Tech. 2 (2013)

[6] Y. Altintas, E. Budak, Analytical Prediction of Stability Lobes in Milling, CIRP Annals - Manufacturing Technology 44 (1995) 357-362

[7] V. Gagnol, T.-P. Le, P. Ray, Modal identification of spindle-tool unit in high-speed machining, Mech. Syst. Signal Process. 25 (2011) 2388-2398

[8] I. Zaghbani, V. Songmene, Estimation of machine-tool dynamic parameters during machining operation through operational modal analysis, Int. J. Machine Tools Manuf. 49 (2009) 947-957

[9] T.L. Schmitz, J.C. Ziegert, C. Stanislaus, A method for predicting chatter stability for systems with speeddependent spindle dynamics, Society of Manufacturing engineers, Technical paper 32 (2003) 1437-1446

[10] B. Badri, M. Thomas, S. Sassi, et al. Instability of high speed machining due to correlation between bearing defect and rotor resonance frequencies. Proceedings of the 27th Seminar on machinery vibration, Canadian Machinery Vibration, 2009

[11] R.P.H. Faassen, N. van de Wouw, J.A.J. Oosterling, H. Nijmeijer, Prediction of regenerative chatter by modelling and analysis of high-speed milling, Int. J. Mach. Tool. Manuf. 43 (2003) 1437-1446

[12] M.A. Alfares, A. Elsharkawy, Effects of axial preloading of angular contact ball bearings on the dynamics of a grinding machine spindle system, J. Mater. Process. Technol. 136 (2003) 48-59

[13] Shin, Yung C., Dynamics of Machine Tool Spindle/Bearing Systems under Thermal Growth, J. Tribol. 4 (1997) 875-882

[14] N. Aktürk, M. Uneeb, R. Gohar, The Effects of Number of Balls and Preload on Vibrations Associated With Ball Bearings, J. Tribol. 119 (1997) 747-753

[15] Jui-Pin Hung, Yuan-Lung Lai, Ching-Yuan Lin, TzuLiang Lo, Modeling the machining stability of a vertical milling machine under the influence of the preloaded linear guide, Int. J. Machine Tools Manuf. 51 (2011) 731739

[16] V. Gagnol, B.C. Bouzgarrou, P. Ray, C. Barra, Modelbased chatter stability prediction for high-speed spindles, I Int. J. Machine Tools Manuf. 47 (2007) 1176-1186

[17] M. Lamraoui, M. Thomas, M. El Badaoui, Cyclostationarity approach for monitoring chatter and tool wear in high speed milling, Mech. Syst. Signal Process. 44 (2014) 177-198

[18] C. Bruenner, G. Spieß, Überwachte Schmierung, Hochgeschwindigkeitsspindeln mit integriertem Ö l-LuftSchmiersystem, Antriebstechnik 9 (2005) 340

[19] E. Abele, A. Schiffler, S. Rothenbuc̈her, System Identification During Milling via Active Magnetic Bearing. Production Engineering 1 (2007) 219-226

[20] M. Kalveram, Analyse und Vorhersage der Rotordynamik und Prozessstabilitat beim Hochgeschwindigkeitsfrasen, Ph.D. thesis, Universitat Dortmund, 2005 
[21] E. Abele, Y. Altintas, C. Brecher, Machine tool spindle units, CIRP Ann. Manufact. Technol. 59 (2010) 781-802

[22] G.H. James, T.G. Carne, J.P. Lauffer, The natural excitation technique (next) for modal parameter extraction from operating structures, J. Anal. Exp. Modal Anal. 10 (1995) 260-277

[23] D.L. Brown, R.J. Allemang, R. Zimmerman, M. Mergeay, Parameter estimation techniques for modal analysis, SAE Technical Paper Series (790221), 1979

[24] H. Vold, G.T. Rocklin, The numerical implication of a multi-input modal estimation method for minicomputers, In Proceedings of the 1st International Modal Analysis Conference (IMAC I), Orlando, Fl, USA, 1985, Society for Engineering Mechanics

[25] S.R. Ibrahim, E.C. Mikulcik, A time domain modal vibration test technique, Shock Vib. Bull. 43 (1973) 21-37

[26] S.A. Zaghlool, Single-station time-domain (sstd) vibration testing technique: Theory and application, J. Sound Vib. 72 (1980) 205-234

[27] J.N. Juang, R.S. Pappa, An eigensystem realization algorithm for modal parameters identification and model reduction, J. Guidance, Control and Dynamics 8 (1985) 620-627

[28] W. Gersch, Estimation of the autoregressive parameters of a mixed autoregressive moving-average time series, IEEE Trans. Automatic Control AC-15 (1970) 583-588
[29] D. Otte, Q. Yang, P. Sas, Analysis of multivariate operating response data by means of arv time series modelling techniques, In 19th International Seminar on Modal Analysis (ISMA 19), Leuven (B), Belgium, 1994. KU Leuven

[30] P. Van Overschee, B. de Moor, A unifying theorem for three subspace system identification algorithms, In American Control Conference, Baltimore, USA, June, 1994

[31] E. Parloo, P. Guillaume, B. Cauberghe, Maximum likelihood identification of non-stationary operational data, J. Sound Vib. 268 (2003) 971-991

[32] Prasenjit Mohanty, Operational Modal Analysis in the Presence of Harmonic Excitations, Technische Universiteit Delft, $\mathrm{PhD}$ thesis, India

[33] R.B. Randall, N. Sawalhi, A new method for separating discrete components from a signal, J. Sound Vib. 45 (2011) 6-9

[34] Zhi-Fang Fu, Jimin He, Modal analysis, ButterworthHeinemann, 2001, p. 304

[35] J. Antoni, R.B. Randall, Unsupervised Noise Cancellation for Vibration Signals: Part II - A Novel Frequency-Domain Algorithm, Mech. Syst. Signal Process. 18 (2004) 103-117 